Title:

Measurement of Photodynamic Therapy Drug Concentrations in a Tissue

Author(s):

Submitted to:
Judith Mourant, CST-4

Irving Bigio, CST-4

Tamara Johnson, CST-4

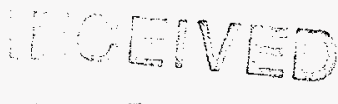

50? 909

$0 \%$

DOE Office of Scientific and Technical Information (OSTI)
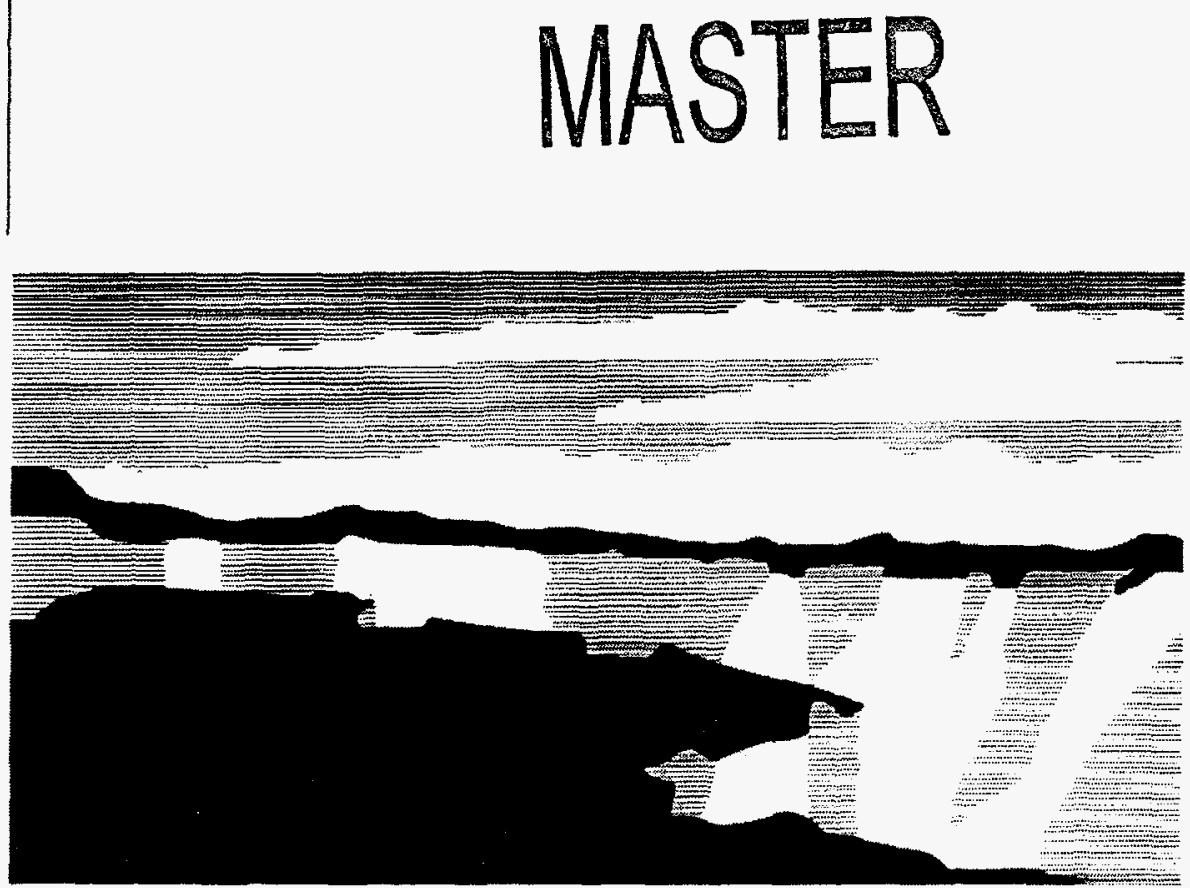

Los Alamos National Laboratory, an affirmative action/equal opportunity employer, is operated by the University of California for the U.S. Department of Energy under contract W-7405-ENG-36. By acceptance of this article, the publisher recognizes that the U.S. Government retains a nonexclusive, royaltyfree license to publish or reproduce the published form of this contribution, or to allow others to do so, for U.S. Government purposes. The Los Alamos National Laboratory requests that the publisher identify this articte as work performed under the auspices of the U.S. Department of Energy. 


\section{DISCLAIMER}

Portions of this document may be illegible in electronic image products. Images are produced from the best available original document. 


\section{DISCLAIMER}

This report was prepared as an account of work sponsored by an agency of the United States Government. Neither the United States Government nor any agency thereof, nor any of their employees, makes any warranty, express or implied, or assumes any legal liability or responsibility for the accuracy, completeness, or usefulness of any information, apparatus, product, or process disclosed, or represents that its use would not infringe privately owned rights. Reference herein to any specific commercial product, process, or service by trade name, trademark, manufacturer, or otherwise does not necessarily constitute or imply its endorsement, recommendation, or favoring by the United States Government or any agency thereof. The views and opinions of authors expressed herein do not necessarily state or reflect those of the United States Government or any agency thereof. 


\title{
Measurement of Photodynamic Therapy Drug Concentrations in a Tissue
}

\author{
Judith Mourant*, Irving Bigio, and Tamara Johnson
}

\begin{abstract}
This is the final report of a one-year, Laboratory-Directed Research and Development (LDRD) project at the Los Alamos National Laboratory (LANL). Photodynamic therapy (PDT) is an experimental treatment modality for cancer in which a photoactive molecule with an affinity for tumors is administered to the patient, then excited by light. Photoactivation creates singlet oxygen consequently killing the tissue. Knowledge of the concentration of the photoactive compound in the tissue is necessary for proper light dosimetry during PDT. Presently, the control of light application is problematic. If too much light is applied, damage to the surrounding tissue will occur. If insufficient light is applied, the targeted tissue volume will remain viable. The ideal implementation of PDT would use a feedback system for light delivery that incorporates the optical properties of the tissue and knowledge of the concentration of the photoactive compound. This project sought to develop a method for measuring photosensitizer concentrations in tissue phantoms that will lead to a noninvasive, endoscopically compatible, in vivo method of measuring PDT drug concentrations.
\end{abstract}

\section{Background and Research Objectives}

Photodynamic therapy (PDT) is an experimental treatment modality for cancer that is nearing Food and Drug Administration (FDA) approval. A photoactive compound (photosensitive drug) with an affinity for cancerous tissue is administered topically, orally, or intravenously. After a variable period of time (typically 6-48 hours) the compound is concentrated selectively in areas of malignancy. The molecule is then photoactivated with a light source of a specific wavelength, creating singlet oxygen preferentially in the tumor/ malignancy. The presence of singlet oxygen in cells has a cytotoxic effect, although the exact mechanism of cell death is still under investigation. Photodynamic therapy is being investigated in several clinical areas including skin cancer, bladder cancer, and carcinoma of organs in the gastrointestinal tract. Photodynamic therapy may also be useful for selective removal of endometrial tissue.

*Principal investigator, e-mail: jmourant@lanl.gov 
Knowledge of the concentration of the photoactive compound present in the tissue is necessary for proper light dosimetry during PDT. Presently, the control of light dosage is problematic. If too much light is applied, damage to the surrounding tissue will occur. If insufficient light is applied, the targeted tissue volume will remain viable. The ideal implementation of PDT would use a feedback system for light delivery that incorporates the optical properties of the tissue and knowledge of the photoactive compound concentrations present in the tissue volume to be treated. Attempts have been made to measure PDT-drug concentrations in tissue by measuring the drug fluorescence. This technique has several problems. The tissue autofluorescence can interfere with the signal from the drug, and both sources of fluorescence can be affected significantly by the patient's physiological condition (blood $\mathrm{pH}$, oxygenation, etc.). Also, due to nonlinearity and saturation effects, the range of measurable drug concentrations by this method is insufficient. Reflectance spectroscopy has also been considered as a method of measuring photosensitizer concentrations in vivo and some preliminary work has been performed. However, this method is complicated by specular reflections, and the experimenters did not make use of the wavelength dependence of the added absorber. When using a technique that was not even applicable to endoscopic techniques, an accuracy of about 20 percent was achieved. Time-domain spectroscopy and frequency-domain methods have also investigated for measuring photosensitizer concentrations. While both of these methods show promise they are more expensive than the steady-state technique outlined here. These techniques have not been fully explored and the need for the technical complexity of these techniques has not been justified.

The goal of this project was to demonstrate that a real-time, fiber-optic-based system can accurately measure PDT sensitizer concentrations by developing a prototype system and demonstrating that there is a correlation between elastic-scatter spectra and the concentration of photosensitizer in a tissue phantom.

\section{Importance to LANL's Science and Technology Base and National R\&D Needs}

Noninvasive optical diagnostics are important to both LANL's strategic goals and national research and development needs. This project involved the development of such a capability for a medical application and enhances the ability of the Laboratory to respond to diagnostics initiatives. This project supports the Laboratory's core competency in Bioscience and Biotechnology. 


\section{Scientific Approach and Results to Date}

The scientific approach used in this project can be divided into three main parts: (1) the development of a tissue phantom, (2) measurement of elastic-scatter signals in tissue phantoms before and after different amounts of an absorber are added, and (3) modeling the elastic-scatter signal to derive absorber (photosensitizer) concentrations.

We have made and tested several tissue phantoms. The most common photosensitizer that has been used is a suspension of polystyrene spheres. Suspensions of spheres were obtained from a commercial supplier and diluted to appropriate concentrations. Unfortunately, we found that it was necessary to check the size of the spheres with a scanning electron microscope to be certain of their size. To simulate tissue with or without PDT photosensitizers present, absorbers such as hemoglobin and a red dye were added. We have also made solid tissue phantoms out of titanium dioxide and a clear plastic resin.

We have demonstrated that we can measure the wavelength dependence of the reduced scattering coefficient and the absorption coefficient of an absorber added to these phantoms. We have compared some of the results that we have obtained for the reduced scattering coefficient of 10 percent whole milk with those found in the literature. The results agree to within a factor of two. Figure 1 is a plot of the absorption of a red dye made in milk compared to the absorption of a clear red dye measured with a standard spectrophotometer.

A code for modeling the transport of photons (by Monte Carlo techniques) through a tissue in a geometry such as is shown in Figure 2, has been developed. This code is different from other similar codes in the way in which the wavelength dependence of scattering and absorption are handled. Also, to the best of our knowledge, other Monte Carlo simulations have not simulated this (very clinically relevant) fiber optic geometry. Results of simulations with this code have been compared to experimental measurements of elastic scatter signals of some of the tissue phantoms described above. Some significant progress was made in that some of the features of the experimental measurements are reproduced in the Monte Carlo results. However, the agreement between simulation and experiment could still be improved upon. We are continuing to work on this aspect of the project.

Finally, we have obtained some interesting results concerning the major factors that determine the elastic scatter signal for small source-detector separations, d. For large d, the elastic-scatter signal is determined by the reduced scattering-cross-section, $\mu_{s}{ }^{\prime}=\mu_{s}(1-g)$, where $\mu_{S}$ is the scattering-cross-section of a single particle, and $g=\langle\cos \theta>$, where $\theta$ is the angle through which a photon scatters. (In general, large values of $\mathrm{g}$ mean that scattering is more forward directed.) For small fiber separations (small $d$ in Figure 2), the situation is more complicated. Scattering at small angles (which is what primarily determines $\mathrm{g}$ ) is not 
important. However, scattering at large angles is very important. This was demonstrated by simulating photon transport through suspensions of 0.483 and $1.85 \mu \mathrm{m}$ radius spheres. The distance, d, between the fibers was $200 \mu \mathrm{m}$ and each fiber was assumed to be $200 \mu \mathrm{m}$ in diameter. Although $\mathrm{g}$ is larger for the $1.85 \mu \mathrm{m}$ radius spheres leading one to expect that the collected photons from the suspension of $1.85 \mu \mathrm{m}$ radius spheres underwent more high angle scattering events, the reverse is true. The probability that a collected photon underwent a high angle scattering event is actually larger for the $1.85 \mu \mathrm{m}$ radius spheres than for the $0.483 \mu \mathrm{m}$ radius spheres. The distribution of angles through which collected photons scattered is plotted in Figure 3 for a suspension of $0.483 \mu \mathrm{m}$ radius spheres and a suspension of $1.85 \mu \mathrm{m}$ radius spheres. 


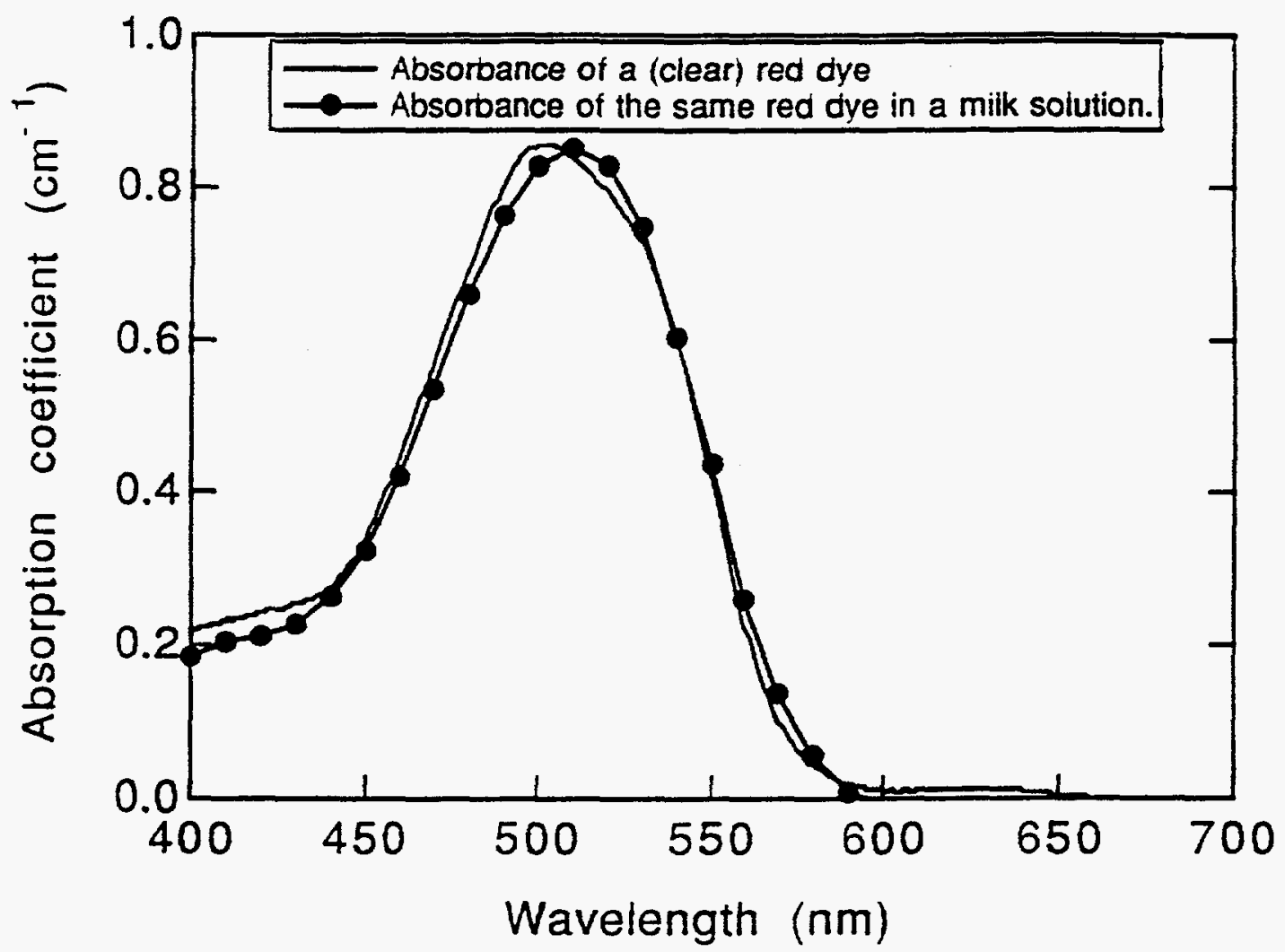

Figure 1. The absorbance of a clear red dye measured in a standard spectrophotometer compared with the measurement of the same red dye in a solution of 10 percent whole milk.

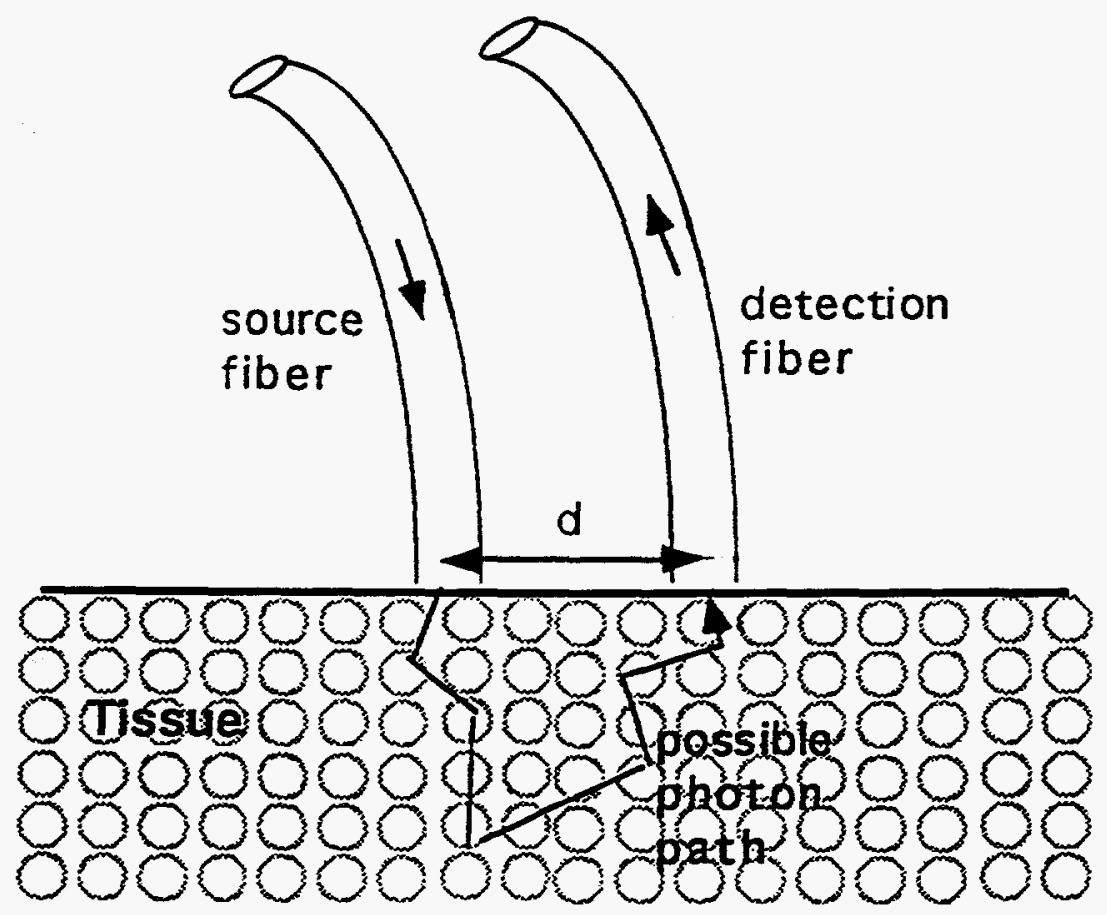

Figure 2. A representative geometry for elastic scatter measurements of tissue. The schematic is not to scale. Fiber separation, d, can range from 0 to approximately $1500 \mu \mathrm{m}$. The diameter of the fibers typically varies from $200-500 \mu \mathrm{m}$. 


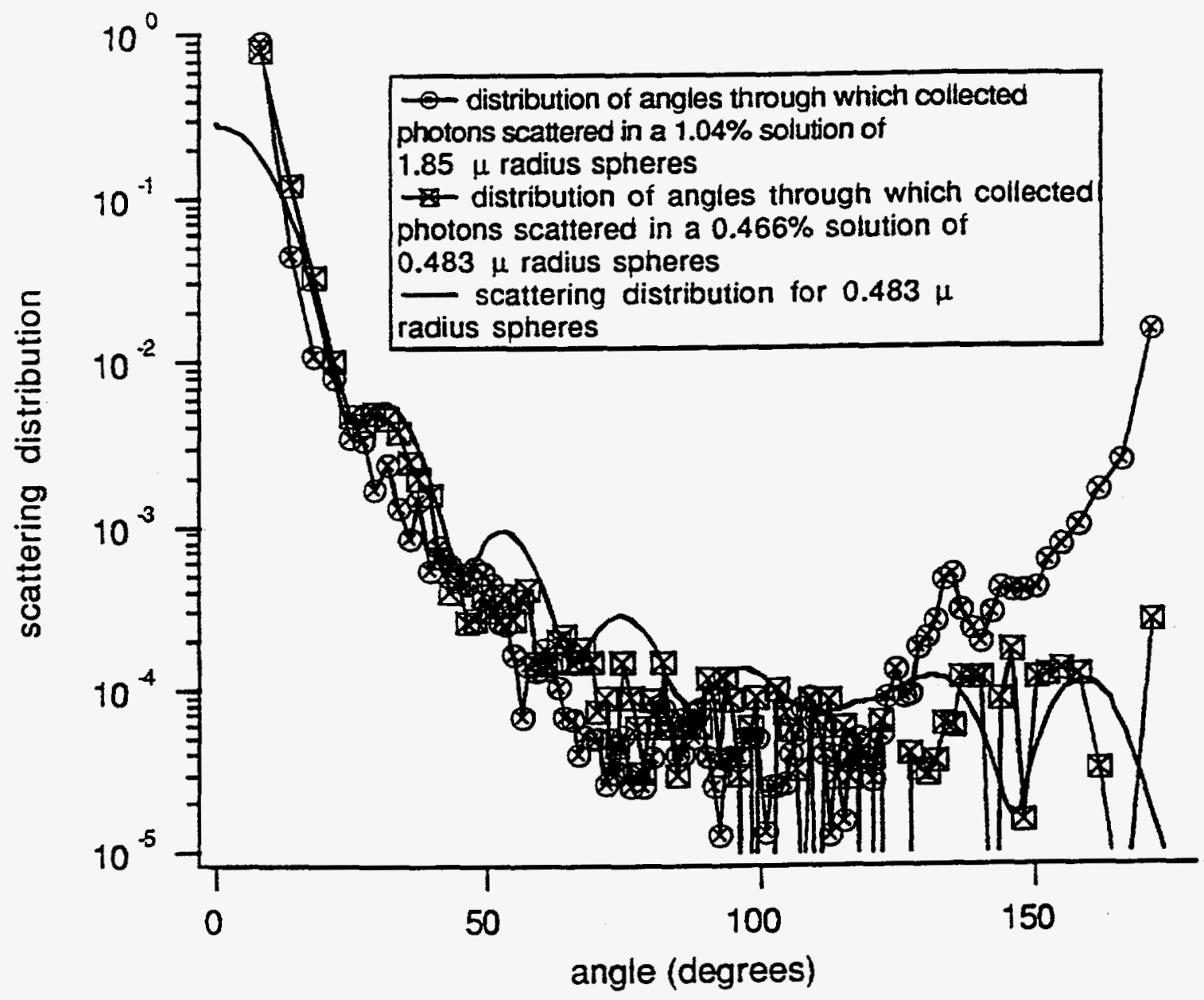

Figure 3. Symbols: distribution of angles through which collected photons scattered. The delivery and collection fibers were both $200 \mu \mathrm{m}$ in diameter and were adjacent to each other. Although the Monte Carlo data is noisy for the $0.483 \mu \mathrm{m}$ radius spheres, it is clear that more high angle scattering events took place in the suspension of $1.85 \mu \mathrm{m}$ radius spheres. The solid line (no symbols) is the angular scatter distribution for $0.483 \mu \mathrm{m}$ radius spheres calculated by Lorenz-Mie theory. 